\title{
L-lysine and L-arginine inhibit the oxidation of lipids and proteins of emulsion sausage by chelating iron ion and scavenging radical
}

\author{
Peng Xu' ${ }^{1}$, Yadong Zheng ${ }^{1}$, Xiaoxu Zhu ${ }^{1}$, Shiyi Li $^{1}$, and Cunliu Zhou ${ }^{1, *}$
}

* Corresponding Author: Cunliu Zhou Tel: +86-551-62919387, Fax: +86-551-62901539,

E-mail: zhouc14@hfut.edu.cn

'School of Food Science and Engineering, Hefei University of Technology, Hefei 230009, China

ORCID

Cunliu Zhou

https://orcid.org/0000-0001-6444-0986

Submitted Aug 21, 2017; Revised Oct 20, 2017; Accepted Dec 1, 2017
Objective: To evaluate the effects of L-lysine (Lys)/L-arginine (Arg) on lipid and protein oxidation of emulsion sausage during storage and its possible mechanism.

Methods: Four samples were prepared based on the presence or absence of additional sodium isoascorbate, Lys, or Arg: sample A (control), sample B ( $0.05 \mathrm{~g}$ of sodium isoascorbate), sample $\mathrm{C}(0.4 \mathrm{~g}$ of Lys), and sample D (0.4 g of Arg). Peroxide value (POV), thiobarbituric reactive substances (TBARS), protein carbonyls and thiols were measured. 2,2-Diphenyl-1-picrylhydrazyl (DPPH) and hydroxyl radical-scavenging, ferrous ion-chelating ability were also measured.

Results: Compared with the control, the sample treated with sodium isoascorbate, Lys or Arg had significantly lower POV during the initial 20 days, TBARS during the initial 15 days. Protein carbonyls were significantly lower compared Sample B, C, and D with A during the later storage (10 to 25 days); basically, protein thiols became lower during storage when the samples were treated with sodium isoascorbate, Lys, or Arg. Both Lys and Arg had weak reducing power but strong ferrous ion-chelating activity and DPPH radical- and hydroxyl radical-scavenging activity.

Conclusion: Both Lys and Arg effectively inhibited the oxidation of lipids and proteins in emulsion sausage by scavenging free radicals and chelating ferrous ions. The results obtained may be favorable for the prevention of lipid and protein oxidation during processing and storage of meat products.

Keywords: Lys/Arg; Meat Products; Proteins; Lipids; Autoxidation

\section{INTRODUCTION}

Meat products are rich in lipids and proteins. Usually, these components are easily oxidized during processing, storage, and circulation owing to high water activity. The oxidation of lipids and proteins has negative effects on the flavor, color, texture, water-holding capacity, nutritional value, and safety of meat products $[1,2]$.

Lipid/protein oxidation is caused by free radicals. It is a typical chain reaction and includes chain initiation, propagation and termination [3]. Some metal ions $\left(\mathrm{Fe}^{2+}, \mathrm{Cu}^{2+}\right.$ etc. $)$ are conducive to electron transfer, which accelerates the formation of free radicals and catalyzes lipid/protein oxidation [4]. Theoretically, substances that can scavenge free radicals and/or chelate metal ions may be effective to suppress lipid/protein oxidation.

Phenolic compounds meet the above requirements. Therefore, some synthetic phenolic antioxidants, such as butylated hydroxyanisole, butylated hydroxytoluene, tertiary butyl hydroquinone, and propyl gallate, exhibit excellent antioxidant properties and are widely used in food industry. However, cancer and deformity have been reportedly caused by excessive intake of the synthetic antioxidants [5]. Therefore, there is an increasing interest in natural antioxidants due to their high performance, low cost, and wide availability. The appli- 
cation of natural antioxidants is restricted because of the complicated extraction process, lower extraction yield, and higher cost. Thus, discovery of not only safe and efficient, but also cheap additive natural antioxidants is necessary.

L-lysine (Lys) was reported to mask bitter, metallic and other undesirable taste due to the replacement of $\mathrm{NaCl}$ with $\mathrm{KCl}[6]$. Both Lys and L-arginine (Arg) were found to decrease the cooking loss and improve the texture of pork sausage $[7,8]$. These two amino acids ameliorated the color and reduced the thawing loss of frozen shrimp. In addition, Lys and Arg are considered natural, commercially available, and widely used in foods [9]. Therefore, their application in meat industry has recently attracted considerable interest. Lys and Arg contain carboxyl $(-\mathrm{COOH})$ and amine $\left(-\mathrm{NH}_{2}\right)$ functional groups. Importantly, some studies showed that Arg had radicalscavenging activity [10]. Lys was also reported to have metalchelating activity [11]. Therefore, it can be deduced that Lys and Arg can prevent the oxidation of lipids and proteins. However, there is only one literature report on the effects of Lys on the lipase activity and lipid oxidation in dry-cured loin process [12]. Up to date, no other literature exists regarding the effects of Lys and Arg on lipid/protein oxidation in emulsified sausage during storage.

Our previous study $[7,8]$ have showed that both Lys and Arg improved the cooking loss, texture and colour of emulsified sausage. Therefore, this paper focused on the effects of Lys or Arg on the oxidation of lipids and proteins in emulsified sausage during storage. Meanwhile, the possible mechanism was discussed by analyzing 2,2-diphenyl-1-picrylhydrazyl $(\mathrm{DPPH})$ and $\mathrm{OH}$ radical scavenging, ferrous ion-chelating ability, and reducing power.

\section{MATERIALS AND METHODS}

\section{Materials and chemicals}

Lys (99.5\%) and $\operatorname{Arg}$ (99.5\%), basic amino acids, were purchased from Shanghai Juyuan Biotechnology Co., Ltd (Shanghai, China). The pHs of a $0.4 \%(\mathrm{~m} / \mathrm{v})$ Lys and Arg aqueous solution were 9.78 and 10.44 at $25^{\circ} \mathrm{C}$, respectively. Salt $(\mathrm{NaCl}>$ 99.1\%) was purchased from Anhui Salt Industry Corp (Anhui, China). Sodium tripolyphosphate, sodium hexametaphosphate and sodium pyrophosphate were purchased from Xuzhou Hengshi Food Co., Ltd (Jiangsu, China).

The following reagents were of analytical grade: trichloroacetic acid (TCA), thiobarbituric acid (TBA), chloroform, dinitrophenylhydrazone (DNPH), bovine serum albumin (BSA), DPPH, 5,5'-dithiobis-(2-nitrobenzoic acid) (DTNB), sodium dodecyl sulfate (SDS), L-cysteine, anhydrous ethanol, ascorbic acid $(\mathrm{Vc})$, ferrozine, ferrous ammonium sulfate $\left(\mathrm{Fe}\left[\mathrm{NH}_{4}\right]_{2}\left[\mathrm{SO}_{4}\right]_{2} \cdot 6 \mathrm{H}_{2} \mathrm{O}\right)$, and potassium ferricyanide $\left(\mathrm{K}_{3}[\mathrm{Fe}\right.$ $\left.(\mathrm{CN})_{6}\right]$ ).

Three batches of chicken breast and pork back fat were purchased from one of the local Carrefour supermarkets (Hefei, China). The chicken breast was thawed for $24 \mathrm{~h}$ at a temperature $2^{\circ} \mathrm{C}$ to $4^{\circ} \mathrm{C}$, and then its visible fat and connective tissue were removed. The chicken meat and pork back fat samples were minced twice with a MG-1220 meat grinder (Dr. Jie, Foshan shunde Jinyimei electric appliance Co., Ltd, Guangdong, China) with a thirty-hole plate with a diameter of $5 \mathrm{~mm}$. The minced chicken meat was packaged and stored at $-18^{\circ} \mathrm{C}$ until use, whereas the treatments were performed at $4^{\circ} \mathrm{C}$.

\section{Preparation of emulsion sausages}

The emulsion sausages were prepared according to the method described by Xu et al [13] with slight modifications. The minced chicken meat, pork back fat and curing agents were fully mixed. Subsequently, the meat mixture was pickled at $4^{\circ} \mathrm{C}$ for $24 \mathrm{~h}$. The above curing agents included: $55 \mathrm{~g}$ of minced chicken meat, $24 \mathrm{~g}$ of pork back fat, $2.3 \mathrm{~g}$ of $\mathrm{NaCl}, 0.1 \mathrm{~g}$ of monosodium glutamate, $0.3 \mathrm{~g}$ of white sugar, $0.3 \mathrm{~g}$ of compound phosphates (the mass ratio of sodium tripolyphosphate, sodium pyrophosphate, and sodium hexametaphosphate was 2:2:1), $13 \mathrm{~g}$ of distilled water, and $5 \mathrm{~g}$ of corn starch. The total weight of the meat mixture and the curing agents was up to $100 \mathrm{~g}$. Four samples were prepared based on the presence or absence of additional sodium isoascorbate, Lys, or Arg: sample A (control), sample B ( $0.05 \mathrm{~g}$ of sodium isoascorbate), sample C $(0.4 \mathrm{~g}$ of Lys), and sample D (0.4 g of Arg). The amount of Lys, Arg, and sodium isoascorbate was determined based on information from previous literature evidences $[7,8,14]$. Here, sodium isoascorbate was used because due to its common commercial application aimed at the prevention of oxidization of proteins and lipids in meat products [14].

The meat mixture was stuffed into a polyethylene casing with a diameter of $15 \mathrm{~mm}$. The raw sausages were cooked in a water bath at $80^{\circ} \mathrm{C}\left( \pm 2^{\circ} \mathrm{C}\right)$ for $30 \mathrm{~min}$. After cooling with tap water for $20 \mathrm{~min}$, the sausages were stored at $25^{\circ} \mathrm{C}$ for subsequent analysis.

\section{Determination of peroxide value}

A volume of $150 \mathrm{~mL}$ petroleum ether $\left(30^{\circ} \mathrm{C}\right.$ to $\left.60^{\circ} \mathrm{C}\right)$ was added to $100 \mathrm{~g}$ of each of the minced sausage samples, followed by stirring at room temperature overnight. The filtrate was obtained by suction filtration. The solvent was removed by reduced-pressure distillation, and the lipid extract of the emulsion sample was obtained and used for peroxide value (POV) analysis.

The POV was determined according to the Chinese national standard (GB/T 5538-2005). Specifically, $5.0 \mathrm{~g}$ of the lipid extract was dissolved with $50 \mathrm{~mL}$ of component solvent (acetic acid:isooctane $=3: 2, \mathrm{v} / \mathrm{v}$ ). The mixture was vigorously shaken to achieve full dissolution of the lipid extract. Then, $0.5 \mathrm{~mL}$ of saturated potassium iodide solution was added to the mixture, which was next left undisturbed in the dark for 
$3 \mathrm{~min}$. Subsequently, $30 \mathrm{~mL}$ of distilled water was added, followed by shading. Further, $0.01 \mathrm{~mol} / \mathrm{L}$ of sodium thiosulfate solution was titrated to the mixture until the blue faded. A volume of $0.5 \mathrm{~mL}$ of starch solution $(1 \%, \mathrm{~m} / \mathrm{v})$ was used as an indicator. The POV $(\mathrm{mmol} / \mathrm{kg})$ was determined by the following equation:

$$
\mathrm{P}=0.5 \times 1,000 \times \Delta \mathrm{V} \times \mathrm{c} \div \mathrm{m}
$$

Here, $\Delta \mathrm{V}$ is the volume of consumed sodium thiosulfate solution $(\mathrm{mL}), \mathrm{c}$ is the concentration of sodium thiosulfate solution $(\mathrm{mol} / \mathrm{L})$, and $\mathrm{m}$ is the mass of the examined lipid $\operatorname{extract}(\mathrm{g})$.

\section{Determination of thiobarbituric reactive substances}

Thiobarbituric reactive substances (TBARS) values were determined using the method described by Han et al [15] with some modifications. Each minced sausage sample of $10 \mathrm{~g}$ was placed in a $100-\mathrm{mL}$ beaker and homogenized with $50 \mathrm{~mL} 7.5 \%$ $(\mathrm{m} / \mathrm{v})$ TCA solutions containing $0.1 \%(\mathrm{~m} / \mathrm{v})$ ethylenediaminetetraacetic acid disoduim (EDTA-2Na) using a homogenizer (IKA, T18 Digital ULTRA TURRAX, Shanghai, China). The meat homogenate was filtered twice with double-layer filter paper. Then, $5 \mathrm{~mL}$ of the filtrate was transferred to a test tube, and $5 \mathrm{~mL}$ of TBA ( $0.02 \mathrm{~mol} / \mathrm{L}$ TBA) solution was added. Subsequently, the mixture was fully mixed, incubated in a water bath at $90^{\circ} \mathrm{C}$ for $40 \mathrm{~min}$ to develop a color, and cooled in a water bath at $25^{\circ} \mathrm{C}$ for $20 \mathrm{~min}$. Next, $5 \mathrm{~mL}$ of chloroform was added and mixed into the mixture which was then left undisturbed until two phases appeared. The TBARS values were expressed as mg malondialdehyde/kg meat sample.

$$
\text { TBARS }(\mathrm{mg} / \mathrm{kg})=\left(\mathrm{A}_{532}-\mathrm{A}_{600}\right) \div 155 \div 10 \times 72.06 \times 1,000
$$

Here, $A_{532}$ and $A_{600}$ is the absorbance of the upper layer at $532 \mathrm{~nm}$ and $600 \mathrm{~nm}$, respectively.

\section{Determination of protein carbonyls}

Protein carbonyls were analyzed using the DNPH method with some modifications [16]. A quantity of $1 \mathrm{~g}$ of minced sausage sample was homogenized $(1,000 \times \mathrm{g}, 30 \mathrm{~s})$ in $20 \mathrm{~mL}$ distilled water using a homogenizer. Two aliquots $(1 \mathrm{~mL})$ were taken from the homogenates and dispensed in a centrifuge tube. They were treated with $1 \mathrm{~mL} 2 \mathrm{~mol} / \mathrm{L} \mathrm{HCl}$ (for protein concentration measurement) and $1 \mathrm{~mL}$ of $2 \mathrm{~mol} / \mathrm{L} \mathrm{HCl}$ containing $0.2 \%(\mathrm{~m} / \mathrm{v}) \mathrm{DNPH}$ (for carbonyl concentration measurement) in the dark for $1 \mathrm{~h}$, respectively. The samples were precipitated with $1 \mathrm{~mL}$ of TCA $(20 \%, \mathrm{~m} / \mathrm{v})$ by centrifugation $(2,000 \times \mathrm{g}, 5$ $\mathrm{min}$ ), and the pellets were washed three times with $1 \mathrm{~mL}$ of a component solvent of ethanol and ethyl acetate (v:v = 1:1) to remove the excessive DNPH. The pellets were then dissolved in $3 \mathrm{~mL}$ of $6 \mathrm{~mol} / \mathrm{L}$ guanidine chloride in a water bath at $37^{\circ} \mathrm{C}$ for $15 \mathrm{~min}$. Further, the samples were centrifuged at $2,000 \times \mathrm{g}$ for $3 \mathrm{~min}$ to remove insoluble fragments. Protein concentration was calculated according to the absorbance at $280 \mathrm{~nm}$ (BSA as a standard). Carbonyls value, expressed as nmol of carbonyl per mg of protein, was calculated using an absorption coefficient of $22,000 \mathrm{M}^{-1} \times \mathrm{cm}^{-1}$ at $370 \mathrm{~nm}$ for protein hydrazone.

\section{Determination of protein thiols}

Protein thiols were determined using the DTNB method with some modifications [17]. The standard curves of the protein concentration and thiols were established using BSA in a $0.1 \mathrm{M}$ Tris buffer ( $\mathrm{pH} 8.0)$ with $5 \%(\mathrm{~m} / \mathrm{v})$ SDS and $200 \mu \mathrm{M}$ of Lcysteine stock solution, respectively. The thiol value was calculated as $\mu \mathrm{M}$ thiol/mg protein.

\section{DPPH radical-scavenging assay}

DPPH radical-scavenging ability was assayed according to a previous procedure with some modifications [18]. A volume of $3 \mathrm{~mL}$ of $0.1 \mathrm{mM}$ DPPH solution (in absolute ethanol) or absolute ethanol was thoroughly mixed with a series of concentrations of Lys, Arg, or ascorbic acid (Vc) aqueous solutions $(0.6 \mathrm{~mL})$, respectively. Considering that $\mathrm{Vc}$ has a strong ability to scavenge free radical and is often used to evaluate free radical-scavenging activity, Vc was chosen as a positive control in the present study. The mixture was incubated for $0.5 \mathrm{~h}$ in the dark at room temperature, and the corresponding absorbance $\left(\mathrm{A}_{1}, \mathrm{~A}_{2}\right)$ at $517 \mathrm{~nm}$ was recorded. In addition, the absorbance $\left(\mathrm{A}_{0}\right)$ of a mixture of $3 \mathrm{~mL} 0.1 \mathrm{mM}$ DPPH solution and $0.6 \mathrm{~mL}$ distilled water at $517 \mathrm{~nm}$ was also recorded. The scavenging rate was calculated by the following equation:

Scavenging rate of DPPH radical $=\left[1-\left(\mathrm{A}_{1}-\mathrm{A}_{2}\right) / \mathrm{A}_{0}\right] \times 100 \%$

\section{Hydroxyl radical-scavenging assay}

Hydroxyl radical-scavenging ability was determined according to an earlier reported method with some modifications [19]. Volumes of $6 \mathrm{~mL}$ of $6 \mathrm{mM}$ salicylic acid-ethanol solution, $6 \mathrm{~mL}$ of $6 \mathrm{mM} \mathrm{FeSO}_{4} \cdot 7 \mathrm{H}_{2} \mathrm{O}$ aqueous solution, and $6 \mathrm{~mL}$ of $6 \mathrm{mM} \mathrm{H}_{2} \mathrm{O}_{2}$ were mixed with $6 \mathrm{~mL}$ of different concentration of Lys, Arg, or Vc. The mixture was vortexed and then incubated in a water bath at $37^{\circ} \mathrm{C}$ for $30 \mathrm{~min}$. The absorbance of the mixture with $\left(A_{1}\right)$ or without salicylic acid $\left(A_{2}\right)$ was recorded at $532 \mathrm{~nm}$. Also, the absorbance of the mixture $\left(\mathrm{A}_{0}\right)$ of salicylic acid ethanol solution $(6 \mathrm{~mL}, 6 \mathrm{mM}), \mathrm{FeSO}_{4} \cdot 7 \mathrm{H}_{2} \mathrm{O}$ aqueous solution $(6 \mathrm{~mL}, 6 \mathrm{mM}), \mathrm{H}_{2} \mathrm{O}_{2}(6 \mathrm{~mL}, 6 \mathrm{mM})$, and distilled water $(6 \mathrm{~mL})$ at $532 \mathrm{~nm}$ was determined. The scavenging rate was obtained using the following equation:

Scavenging rate of hydroxyl radical

$$
=\left[1-\left(\mathrm{A}_{1}-\mathrm{A}_{2}\right) / \mathrm{A}_{0}\right] \times 100 \%
$$




\section{Ferrous ion-chelating ability}

Ferrous ion-chelating ability was determined according to the method described by Senevirathne et al [20] with some modifications. Specifically, $5.0 \mathrm{~mL}$ of the different concentrations of Lys, Arg, or EDTA-2Na solution, $0.1 \mathrm{~mL}$ of ferrous chloride solution $(2.0 \mathrm{mmol} / \mathrm{L})$ and $0.2 \mathrm{~mL}$ of ferrozine $(5.0 \mathrm{mmol} / \mathrm{L})$ were added to a tube, respectively. The mixture was fully mixed for $10 \mathrm{~min}$. The absorbance of the mixture $\left(\mathrm{A}_{1}\right)$ was recorded at $562 \mathrm{~nm}$. Here, EDTA-2Na, an important metal-chelating agent, was chosen as reference to evaluate iron ion-chelating activity. In addition, $0.1 \mathrm{~mL}$ of ferrous chloride solution or 5.0 $\mathrm{mL}$ of the different concentrations of Lys, Arg, or EDTA-2Na solution in the above mixture was substituted with the equal volume of distilled water, respectively. The corresponding absorbance $\left(\mathrm{A}_{2}\right.$ or $\left.\mathrm{A}_{0}\right)$ was also determined. The ferrous ionchelating ability was calculated by the following equation:

The ferrous ion-chelating ability $=\left[1-\left(\mathrm{A}_{1}-\mathrm{A}_{2}\right) / \mathrm{A} 0\right] \times 100 \%$

\section{The content of free iron in sausage}

Free iron content was determined according to the method described by Senevirathne et al [20] with some modifications. A minced sample (10 g) was homogenized in $40 \mathrm{~mL}$ of $0.02 \%$ $(\mathrm{m} / \mathrm{v})$ ascorbic acid solution using a homogenizer and filtrated. A volume of $5 \mathrm{~mL}$ of the filtrate was mixed with $1 \mathrm{~mL}$ of $5 \mathrm{mM}$ ferrozine solutions and reacted for $10 \mathrm{~min}$. The absorbance was determined at $562 \mathrm{~nm}$. Finally, the standard curve was obtained according to a series of different concentrations of $\mathrm{Fe}^{2+}$ solutions $\left(\mathrm{Fe}\left(\mathrm{NH}_{4}\right)_{2}\left(\mathrm{SO}_{4}\right)_{2} \cdot 6 \mathrm{H}_{2} \mathrm{O}\right.$ in $0.02 \%$ $(\mathrm{m} / \mathrm{v})$ ascorbic acid solution). The results were expressed as $\mathrm{mg} / 100 \mathrm{~g}$ sample.

\section{Measurement of the reducing power}

$\mathrm{Vc}$ was chosen as a reference to determine the reducing power of Lys and Arg based on the previous procedure with some modifications [21]. Specifically, $0.4 \mathrm{~mL}$ of Lys, Arg, or Vc so- lution was mixed with $2.5 \mathrm{~mL}$ of phosphate buffer $(200 \mathrm{mM}$, $\mathrm{pH}$ 6.6) and $2.5 \mathrm{~mL}$ of $1 \%$ potassium ferricyanide, and the mixture was then incubated in a water bath at $50^{\circ} \mathrm{C}$ for $20 \mathrm{~min}$. The resulting solution was immediately cooled, mixed with $2.5 \mathrm{~mL}$ of $10 \%$ trichloroacetic acid, and centrifuged at $1,800 \times$ $\mathrm{g}$ for $10 \mathrm{~min}$. A $2.5 \mathrm{~mL}$ of the supernatant fraction was mixed with $2.5 \mathrm{~mL}$ of distilled water and $0.5 \mathrm{~mL}$ of $0.1 \%$ ferric chloride. After $10 \mathrm{~min}$, the absorbance of the resulting mixture was determined at $700 \mathrm{~nm}$.

\section{Statistical analysis}

Analysis of variance was used to determine the significance of the differences between samples at $\mathrm{p}<0.05$ by $t$-test. The means and standard errors were determined using Excel (Microsoft Office 2010). Correlation analysis was used by SPSS 16.0 software (SPSS Inc., Chicago, IL, USA).

\section{RESULTS AND DISCUSSION}

\section{Oxidation of lipids and proteins}

POV is a common indicator reflecting the primary oxidation of lipids. As can be seen in Table 1, the POV values in all cases initially increased but then decreased during storage. Hydroperoxide was unstable and easy to decompose into secondary oxidation products. The formation of hydroperoxide might have been faster than its decomposition at the initial stage of lipid oxidation, thereby leading to the increase of POV. Reversely, the decomposition of hydroperoxide might have prevailed over its formation at the later stage of lipid oxidation, contributing to the decrease in hydroperoxide levels. Sodium isoascorbate-, Lys-, or Arg-treated sausages had significantly lower POV values than the control during the initial 20 days, showing that these agents inhibited the lipid oxidation in the emulsion sausage. The POV values of the control reached the maximum value $(1.39 \pm 0.04)$ on day 20 . However, the POV values of the Lys- or Arg-treated sausages reached

Table 1. Changes in POV and TBARS of emulsion sausages during storage

\begin{tabular}{|c|c|c|c|c|c|c|}
\hline \multirow{2}{*}{ Item } & \multirow{2}{*}{ Sample ${ }^{1)}$} & \multicolumn{5}{|c|}{ Storage time } \\
\hline & & 5 & 10 & 15 & 20 & 25 \\
\hline \multirow[t]{4}{*}{ POV } & A & $0.36 \pm 0.05^{a y}$ & $1.11 \pm 0.05^{\mathrm{av}}$ & $0.93 \pm 0.06^{\mathrm{aw}}$ & $1.39 \pm 0.04^{\text {au }}$ & $0.57 \pm 0.07^{\mathrm{ax}}$ \\
\hline & B & $0.16 \pm 0.01^{b w}$ & $0.50 \pm 0.05^{\mathrm{cv}}$ & $0.54 \pm 0.03^{b v}$ & $0.63 \pm 0.03^{\text {bu }}$ & $0.53 \pm 0.01^{\mathrm{av}}$ \\
\hline & C & $0.14 \pm 0.00^{c x}$ & $0.70 \pm 0.09^{b u}$ & $0.39 \pm 0.02^{\mathrm{cw}}$ & $0.42 \pm 0.00^{d v}$ & $0.54 \pm 0.03^{a \mathrm{u}}$ \\
\hline & $D$ & $0.13 \pm 0.03^{\mathrm{cw}}$ & $0.54 \pm 0.06 b^{\text {cu }}$ & $0.40 \pm 0.00^{\text {cuv }}$ & $0.44 \pm 0.00^{\mathrm{cu}}$ & $0.36 \pm 0.01^{b v}$ \\
\hline \multirow[t]{4}{*}{ TBARS } & A & $4.32 \pm 0.05^{\mathrm{ax}}$ & $4.39 \pm 0.10^{\mathrm{ax}}$ & $5.18 \pm 0.01^{\mathrm{av}}$ & $4.87 \pm 0.11^{\mathrm{bcw}}$ & $5.75 \pm 0.01^{\mathrm{cu}}$ \\
\hline & B & $2.88 \pm 0.00^{y}$ & $3.69 \pm 0.15^{\mathrm{cx}}$ & $4.08 \pm 0.04^{\mathrm{cw}}$ & $4.66 \pm 0.07^{\mathrm{cv}}$ & $5.21 \pm 0.07^{d u}$ \\
\hline & $C$ & $3.42 \pm 0.03^{\text {by }}$ & $3.92 \pm 0.03^{b x}$ & $4.20 \pm 0.04 b^{c w}$ & $4.88 \pm 0.00^{\mathrm{bv}}$ & $6.40 \pm 0.03^{b u}$ \\
\hline & D & $3.53 \pm 0.08^{\text {by }}$ & $4.11 \pm 0.11^{b x}$ & $4.37 \pm 0.05^{\mathrm{bw}}$ & $5.07 \pm 0.05^{\text {av }}$ & $6.79 \pm 0.05^{\text {au }}$ \\
\hline
\end{tabular}

POV, peroxide value; TBARS, thiobarbituric reactive substances.

1) A: control, without Lys or Arg; B: $0.05 \mathrm{~g}$ sodium isoascorbate; C: $0.4 \mathrm{~g}$ Lys; and D: $0.4 \mathrm{~g}$ Arg.

The letters $\left({ }^{-c}\right)$ in the same column indicate the presence of significant differences $(p<0.05)$ between different samples at the same storage time. The different letters $\left({ }^{(u-y}\right)$ in the same row mean that there are significantly differences $(p<0.05)$ for the same sample at different storage time. 
the maximum levels of $0.70 \pm 0.09$ and $0.54 \pm 0.06 \mathrm{mmol} / \mathrm{kg}$, respectively, on day 10 , which was much lower than that of the control at the corresponding stage, indicating that Lys/Arg was effective in inhibiting the generation of hydroperoxide.

TBARS is the most widely used direct index that reflects the level of lipid oxidation in meat products. In our investigation, we found that in all cases, TBARS gradually increased with the prolongation of storage time (Table 1), meaning that the oxidation degree increased over time. Lys- or Arg-treated sausages had significantly lower TBARS values than the control during the initial 15 days, which indicated that both Lys and Arg were able to inhibit lipid oxidation. Similarly, Lys was reported to decrease the TBARS values in dry-cured loins [22]. However, basicially, Lys- or Arg-treated sausages had significantly $(\mathrm{p}<0.05)$ higher TBARS values than the control during the final stage of storage (20 to 25 days), showing that Lys or Arg displayed pro-oxidant effects. Similarly, rosemary extract was also found to have pro-oxidant effects in frankfurters [23]. The sodium isoascorbate-treated sausages exhibited lower TBARS values $(\mathrm{p}<0.05)$ than the control and Lys- or Arg-treated sausages throughout storage time. This result indicated that sodium isoascorbate was more effective in hindering lipid oxidation than Lys or Arg. The Lys-treated ones had slightly ( $p>0.05$ ) lower TBARS values than those of the Arg-treated sausages during the initial 15 days but had considerably lower TBARS values during the later phases of storage $(\mathrm{p}<0.05)$, showing that Lys may be more effective than Arg in the suppression of lipid oxidation in sausage samples.

Meat proteins are prone to oxidation which results in the formation of carbonyl groups. Carbonyl content is one of the most general parameters to evaluate protein oxidation [24]. In all cases examined in our study, the carbonyl content in the samples significantly increased $(\mathrm{p}<0.05)$ during storage and reached its highest values on day 25 (Table 2). These results clearly showed that oxidation of proteins occurred during storage. During storage, sodium isoascorbate-, Lys- or Arg-treated sausages had significantly $(\mathrm{p}<0.05)$ lower carbonyl values than the control, indicating that these reagents inhibited the oxidation of proteins during 10 to 25 -day of storage. The carbonyl levels were not significantly ( $\mathrm{p}>0.05)$ different from those in the samples treated with sodium isoascorbate, Lys, or Arg, respectively.

Theoretically, the oxidation of proteins causes a decrease in thiol content [25]. Also, the amount of thiol in all cases slightly even significantly decreased during storage. Basicially, sodium isoascorbate-, Lys-, or Arg-treated sausages showed significantly lower $(\mathrm{p}<0.05)$ thiol levels than those in the control during storage, indicating that sodium isoascorbate, Lys, and Arg accelerated the loss of thiol. Zhang et al [22] found that sage also accelerated the loss of thiol although it prevented lipid and protein oxidation. Similarly, Jongberg et al [26] revealed that the addition of white grape extract to beef patties intensified the loss of thiol but slowed down myosin cross-link formation. Lutolf et al [27] reported that the positive charges from arginine decreased accelerated Michael-type reactivity of thiols. Takeo and Kyozo [28] showed that there are a variety of $\alpha, \beta$-unsaturated compounds in meat products. Therefore, it is possible that in our experiments, the $\alpha, \beta$-unsaturated compounds reacted with thiols in the presence of positively charged Lys/Arg, ultimately contributing to the decrease in thiol levels.

The present results indicated that the oxidations of lipids and proteins were slow compared the sample treated with Lys/Arg and the control. In addition, Okon et al [29] showed that in meat products, above $56 \%$ Arg was lost after 4 months of storage. Also, Hes and Pyrcz [30] showed that in stored raw Polish sausage, the half-life period of Lys was near 43 days. The results indicated that in meat products, Lys and Arg were relatively stable during storage. Therefore, it can be concluded that Lys/Arg may contribute to the declined oxidations of lipids and proteins. However, meat products are complex systems containing a variety of reducive and oxidative ingredients; therefore, it is difficult to determine the specific roles of Lys and Arg in inhibiting the oxidation of lipids and proteins.

Table 2. The changes in carbonyl and thiol value of emulsion sausages during storage

\begin{tabular}{|c|c|c|c|c|c|c|}
\hline \multirow{2}{*}{ Item } & \multirow{2}{*}{ Sample ${ }^{1)}$} & \multicolumn{5}{|c|}{ Storage time } \\
\hline & & 5 & 10 & 15 & 20 & 25 \\
\hline \multirow[t]{4}{*}{ Carbonyl } & A & $2.32 \pm 0.11^{\mathrm{ax}}$ & $2.70 \pm 0.14^{\operatorname{awx} x}$ & $3.17 \pm 0.10^{\mathrm{aww}}$ & $3.48 \pm 0.10^{\text {auv }}$ & $3.71 \pm 0.12^{\text {auv }}$ \\
\hline & B & $1.97 \pm 0.04^{\mathrm{abw}}$ & $2.15 \pm 0.07^{b w}$ & $2.47 \pm 0.06^{\mathrm{bv}}$ & $2.78 \pm 0.11^{\text {buv }}$ & $3.01 \pm 0.13^{\text {bu }}$ \\
\hline & C & $1.84 \pm 0.05^{b x}$ & $2.13 \pm 0.11^{b w x}$ & $2.49 \pm 0.13^{\mathrm{bvw}}$ & $2.81 \pm 0.13^{b u v}$ & $3.08 \pm 0.10^{\text {bu }}$ \\
\hline & D & $1.95 \pm 0.07^{\mathrm{abx}}$ & $2.10 \pm 0.13^{b w x}$ & $2.54 \pm 0.15^{b w w}$ & $2.88 \pm 0.19^{b u v}$ & $3.18 \pm 0.04^{\text {bu }}$ \\
\hline \multirow[t]{4}{*}{ Thiol } & A & $58.0 \pm 0.9^{\text {au }}$ & $52.1 \pm 1.4^{\mathrm{av}}$ & $47.6 \pm 0.6^{\mathrm{av}}$ & $42.8 \pm 1.1^{\mathrm{aw}}$ & $39.7 \pm 1.0^{\mathrm{aw}}$ \\
\hline & B & $55.4 \pm 0.8^{\mathrm{abu}}$ & $46.7 \pm 0.8^{\mathrm{bv}}$ & $41.9 \pm 0.9^{b w}$ & $37.8 \pm 0.9^{b x}$ & $35.7 \pm 1.0^{b x}$ \\
\hline & C & $55.6 \pm 0.9^{\mathrm{abu}}$ & $48.9 \pm 0.9^{\mathrm{abv}}$ & $43.4 \pm 0.9^{b w}$ & $40.0 \pm 0.8^{\mathrm{abw} x}$ & $37.1 \pm 1.1^{\mathrm{abx}}$ \\
\hline & D & $53.7 \pm 1.0^{\text {bu }}$ & $47.0 \pm 1.0^{\mathrm{abv}}$ & $42.6 \pm 0.9^{b w}$ & $39.1 \pm 1.3^{\mathrm{abwx}}$ & $36.2 \pm 0.7^{b x}$ \\
\hline
\end{tabular}

\footnotetext{
${ }^{1)} \mathrm{A}$ : control, without Lys or Arg; B: $0.05 \mathrm{~g}$ sodium isoascorbate; C: $0.4 \mathrm{~g}$ Lys; and D: $0.4 \mathrm{~g}$ Arg.

The letters $\left({ }^{a-c}\right)$ in the same column mean there are significant differences $(p<0.05)$ between different samples at the same storage times. The different letters $\left({ }^{(-y}\right)$ in the same row indicate that there are significant differences $(p<0.05)$ for the same sample at different storage times.
} 
Lipid oxidation is a typical free-radical chain reaction which usually includes three steps: chain initiation, propagation, and termination [31]. The lipid-derived radicals and/or hydroperoxides were found to promote protein oxidation [32]. Meanwhile, the oxidation of myoglobin released iron ions, which in turn accelerated lipid oxidation [33]. The results of the present study showed that a positive correlation existed between protein carbonyls and TBARS $(r=0.84$; $\mathrm{p}<0.01)$, which was in accordance with the hypothesis that the oxidation of lipid and protein simultaneously occurred and mutually promoted in meat products. The substances which can scavenge free radicals and/or chelate metal ions effectively hinder lipid/protein oxidation. Some reports showed that Lys and Arg can scavenge free radicals [10], chelate metal ions $[34,35]$ and have reducing power [36]. This supplied a plausible explanation that Lys and Arg are effective in the prevention of lipids and proteins from oxidation. To clarify the role of Lys and Arg in the inhibition of lipid and protein oxidation, DPPH and $\mathrm{OH}$ radical-scavenging assays were conducted, and ferrous ion-chelating ability and reducing power were investigated.

\section{DPPH and $\mathrm{OH}$ radical-scavenging assays}

DPPH radical-scavenging ability is regarded as its total capacity of scavenging free radicals [37]. The $\mathrm{OH}$ radical, which is the most reactive and powerful oxidizing active oxygen, is able to directly react with lipids and its primary oxidation products $(\mathrm{ROOH})$ [38]. Therefore, the scavenging activity of the $\mathrm{OH}$ radical is an important indicator for the evaluation of the capacity of antioxidants to prevent lipid and protein oxidation [39]. As illustrated in Figure 1 and 2, Lys, Arg, and Vc

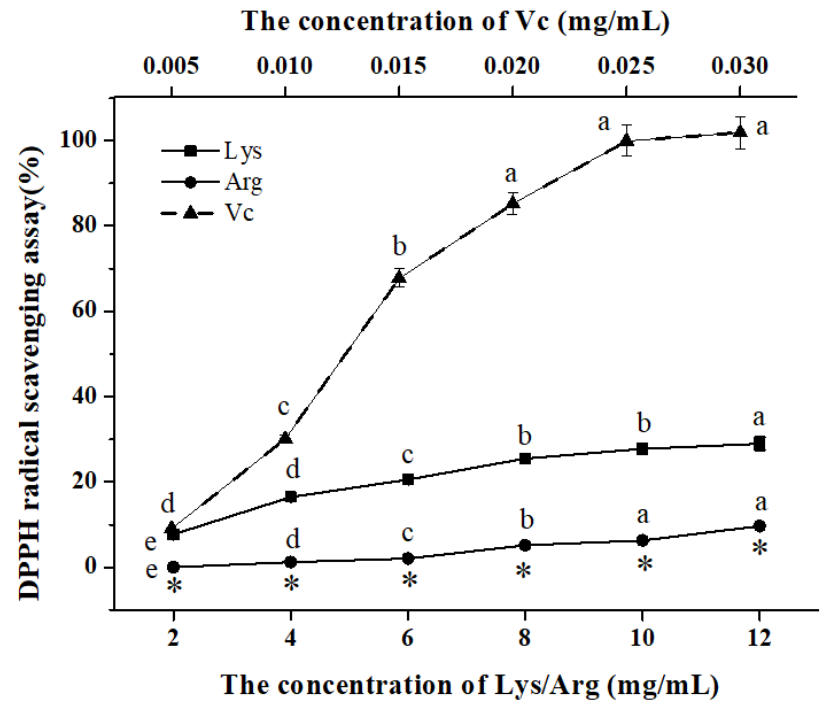

Figure 1. Scavenging activity of of L-lysine (Lys), L-arginine (Arg), and ascorbic acid (Vc) against the 2,2-diphenyl-1-picrylhydrazyl (DPPH) radical. Different letters in the same sample indicate significant difference $(p<0.05) ;$ * means there were significant different at the same concentration between Lys and Arg $(p<0.05)$.

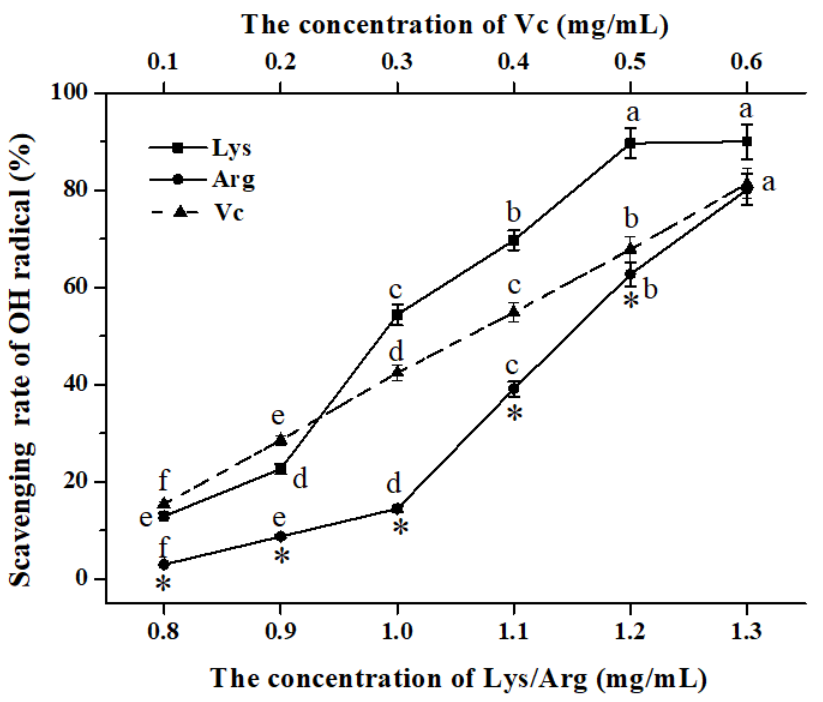

Figure 2. Scavenging activity of $\mathrm{OH}$ radical of L-lysine (Lys), L-arginine (Arg), and ascorbic acid (Vc). Different letters in the same sample indicate significant difference $(p<0.05) ;{ }^{*}$ means there were significant different at the same concentration between Lys and $\operatorname{Arg}(p<0.05)$.

had strong scavenging activity against $\mathrm{DPPH}$ and $\mathrm{OH}$ radicals. Moreover, the rates of scavenging the two radicals increased with the rise in Lys, Arg, or Vc levels. Vc is able to scavenge $\mathrm{DPPH}$ radical because it can convert a DPPH radical to a stable DPPH2 molecular by providing an electron or proton [40]. Theoretically, Vc has strong scavenging activity at the high concentrations. Vc had the strongest scavenging ability against $\mathrm{DPPH}$ and $\mathrm{OH}$ radicals, followed by Lys and Arg. The rate of $\mathrm{DPPH}$ radical scavenging was lower than $50 \%$ in all the tested concentrations of Lys and Arg. A rate of 50\% OH radical scavenging was detected at a concentration of 0.99 $\mathrm{mg} / \mathrm{mL}$ Lys, $1.15 \mathrm{mg} / \mathrm{mL}$ Arg, and $0.35 \mathrm{mg} / \mathrm{mL}$ Vc, respectively. Compared with DPPH radical, $\mathrm{OH}$ radical was easier to scavenge by Lys and Arg. The capacity of Lys/Arg to scavenge $\mathrm{DPPH}$ and $\mathrm{OH}$ radicals by may play an important role in blocking the propagation of free radicals during lipid and protein oxidation.

\section{Ferrous ion-chelating ability}

$\mathrm{Fe}^{2+}$ is considered a strong pro-oxidant that causes the production of reactive oxygen species. Fiorucci et al [41] showed that $\mathrm{Fe}^{2+}$ generated lipid peroxide and accelerated lipid oxidation. Usually, the release of iron ions in meat products is considerable owing to the oxidation of hemoglobin/myoglobin [23]. As shown in Figure 3, we found that Lys, Arg, and EDTA$2 \mathrm{Na}$ had a strong ferrous ion-chelating ability. Moreover, the ferrous ion-chelating rate significantly increased with the elevation of Lys, Arg, and EDTA-2Na levels. The $\mathrm{IC}_{50}$ values of Lys, Arg, and EDTA-2Na were 23.2, 42.5, and $7.0 \mu \mathrm{g} / \mathrm{mL}$, respectively. This suggested that ferrous ion-chelating ability decreased in the following order: EDTA-2Na $>$ Lys $>$ Arg. Ge- 


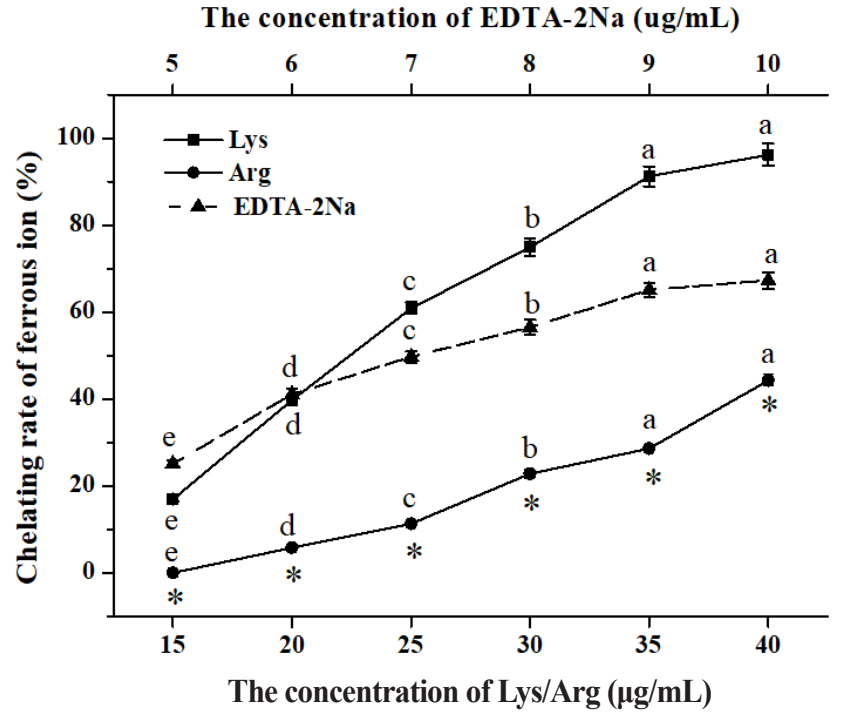

Figure 3. Ferrous ion-chelating ability of L-lysine (Lys), L-arginine (Arg), and ethylenediaminetetraacetic acid disoduim (EDTA-2Na). Different letters in the same sample indicate significant difference $(p<0.05) ;{ }^{*}$ means there were significant different at the same concentration between Lys and Arg $(p<0.05)$.

nerally, the compounds with structures containing two or more of the functional groups $-\mathrm{OH},-\mathrm{SH},-\mathrm{COOH},-\mathrm{C}=\mathrm{O}$, $-\mathrm{NR}_{2},-\mathrm{S}-$, and $-\mathrm{O}-$ in a favorable structure-function configuration have chelating activity [42]. Lys and Arg have $\mathrm{COOH}$ and $-\mathrm{NR}_{2}$ groups, and thus, theoretically, Lys and Arg have the capacity to chelate metallic ions. This view was supported by many earlier research findings. For example, Lys was reported to chelate iron ions [43]. In addition, by conducting an analysis of the IR spectrum, Bai et al [36] confirmed that Arg was also able to chelate iron ions. Further, the present findings showed that the concentration of free iron in the sausages treated with Lys and Arg was $0.176 \pm 0.013 \mathrm{mg} / 100 \mathrm{~g}$ and $0.164 \pm 0.001 \mathrm{mg} / 100 \mathrm{~g}$, respectively, which was significantly lower than that in the control $(0.198 \pm 0.014 \mathrm{mg} / 100 \mathrm{~g})$. Similarly, Bai et al [36] reported that Arg significantly reduced the content of free iron in hemoglobin. Therefore, it may be concluded that the chelation between Lys/Arg and ferrous ions in the sausage samples decreased the concentration of free ferrous ions, ultimately hindering the oxidation of lipids and proteins.

\section{Reducing power}

Reducing power is another important parameter used to evaluate antioxidant capacity. As illustrated in Figure 4, Arg showed a poor reducing power in all tested concentrations. Although Lys had a relatively stronger reducing power than Arg, it was generally exceedingly weak. Our results suggested that reducing power exerted a minor impact on the oxidation of lipids and proteins. The reducing power of an antioxidant is generally realized by donating a hydrogen atom and/or breaking

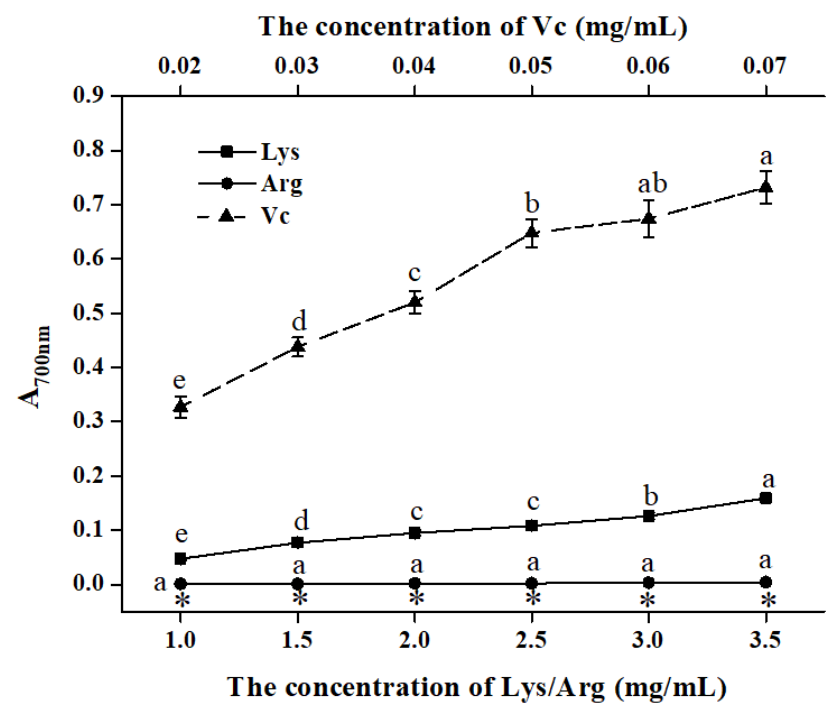

Figure 4. Reducing power of L-lysine (Lys), L-arginine (Arg), and ascorbic acid $(\mathrm{Vc})$. Different letters in the same sample indicate significant difference $(p<0.05)$; * means there were significant different at the same concentration between Lys and $\operatorname{Arg}(\mathrm{p}<0.05)$.

the free radical chain [44]. Phenolic compounds can provide a hydrogen atom because of their ability to form a stable phenoxy radical [22]. However, in contrast to phenolic compounds, amino acids are poor electronic donors owing to the existence of an electron-withdrawing group (carbonyl) or a strong covalent bond (amino group) [45], which may contribute to the poor reducing power of Lys/Arg. Therefore, reducing power is not the crucial factor that affects the antioxidant potential of Lys/Arg.

Based on the present findings, it could be concluded that Lys/Arg are effective in scavenging free radicals and chelating free metallic ions, which may block the propagation of free radical chain reactions and the decrease catalytic capacity of ferrous ions, ultimately preventing lipid and protein oxidation.

\section{CONCLUSION}

Basicially, Lys/Arg significantly decreased the POV, TBARS, and carbonyl values but accelerated the loss of thiol. Lys and Arg had a weaker reducing power but a strong capacity to chelate ferrous ions and scavenge DPPH and hydroxyl radicals. The present results show that Lys and Arg effectively inhibit lipid and protein oxidation by scavenging free radicals and chelating ferrous ions, which can be of substantial importance to the meat industry.

\section{CONFLICT OF INTEREST}

We certify that there is no conflict of interest with any financial 
organization regarding the material discussed in the manuscript.

\section{ACKNOWLEDGMENTS}

This work was supported by the National Natural Science Foundation of China (No. 21542008).

\section{REFERENCES}

1. Estévez M. Protein carbonyls in meat systems: a review. Meat Sci 2011;89:259-79.

2. Kaja T, Johnerik H, Henrikj A, et al. Monitoring of warmedover flavour in pork using the electronic nose-correlation to sensory attributes and secondary lipid oxidation products. Meat Sci 2008;80:1254-63.

3. Frankel EN. Volatile lipid oxidation products. Prog Lipid Res 1983;22:1-33.

4. Ladikos D, Lougovois V. Lipid oxidation in muscle foods: a review. Food Chem 1990;35:295-314.

5. Halliwell B, Aeschbach R, Löliger J, et al. The characterization of antioxidants. Food Chem Toxicol 1995;33:601-17.

6. dos Santos BA, Campagnol PC, Morgano MA, et al. Monosodium glutamate, disodium inosinate, disodium guanylate, lysine and taurine improve the sensory quality of fermented cooked sausages with 50\% and $75 \%$ replacement of $\mathrm{NaCl}$ with KCl. Meat Sci 2014; 96:509-13.

7. Zhou CL, Li J, Tan SJ. Effect of L-lysine on the physicochemical properties of pork sausage. Food Sci Biotechnol 2014;23: 775-80.

8. Zhou CL, Li J, Tan SJ, et al. Effects of L-arginine on physicochemical and sensory characteristics of pork sausage. Adv J Food Sci Technol 2014;6:660-7.

9. Wachirasiri K, Wanlapa S, Uttapap D, et al. Use of amino acids as a phosphate alternative and their effects on quality of frozen white shrimps (Penaeus vanamei). LWT-Food Sci Technol 2016;69:303-11.

10. Böger RH, Bode-Böger SM, Mügge A, et al. Supplementation of hypercholesterolaemic rabbits with $\mathrm{L}$-arginine reduces the vascular release of superoxide anions and restores $\mathrm{NO}$ production. Atherosclerosis 1995;117:273-84.

11. Van CD, Gross E. Effect of histidine and certain other amino acids on the absorption of iron-59 by rats. J Nutr 1969;99:6874.

12. Zhang YW, Zhang L, Hui T, Guo XY, Peng ZQ. Influence of partial replacement of Nacl by kcl, L-histidine and L-lysine on the lipase activity and lipid oxidation in dry-cured loin process. LWT-Food Sci Technol 2015;64:966-73.

13. Xu P, Zheng YD, Zhu XX, Li SY, Zhou CL. Effects of different basic amino acids on quality properties of emulsion-type sausage. Meat Res 2017;31:5-9. (in Chinese)

14. Vaudagna SR, Gonzalez CB, Guignon B, et al. The effects of high hydrostatic pressure at subzero temperature on the quality of ready-to-eat cured beef carpaccio. Meat Sci 2012;92:575-81.

15. Han YQ, Zhang QQ, Xu XL, et al. Effect of high pressure processing on refrigerated shelf-life of sliced smoked cooked ham. Trans Chinese Soc Agric Eng 2009;25:305-11.

16. Rodríguez-Carpena JG, Morcuende D, Estévez M. Avocado by-products as inhibitors of color deterioration and lipid and protein oxidation in raw porcine patties subjected to chilled storage. Meat Sci 2011;89:166-73.

17. Zakrys-Waliwander PI, O'Sullivan MG, O’Neill EE, et al. The effects of high oxygen modified atmosphere packaging on protein oxidation of bovine $M$. longissimus dorsi muscle during chilled storage. Food Chem 2012;131:527-32.

18. Brand-Williams W, Cuvelier ME, Berset C. Use of a free radical method to evaluate antioxidant activity. LWT-Food Sci Technol 1995;28:25-30.

19. Xu YT, Zang JX, Song ZZ, Xue JL, Sun Y. Preparation and invitro antioxidant activity of proteins from the larvae of black soldier fly, (Diptera: Stratiomyidae). J Nucl Agric Sci 2014;28: 2001-9.

20. Senevirathne M, Kim SH, Siriwardhana N, et al. Antioxidant potential of "Ecklonia cava" on reactive oxygen species scavenging, metal chelating reducing power and lipid peroxidation inhibition. Food Sci Technol Int 2006;12:27-38.

21. Yue JM, Biao PU, Chen AJ, et al. Antioxidant activity in vitro of polysaccharides with different molecular weights from truffles. Food Sci 2013;34:127-31. (In Chinese).

22. Zhang L, Lin YH, Leng XJ, et al. Effect of sage (Salvia officinalis) on the oxidative stability of Chinese-style sausage during refrigerated storage. Meat Sci 2013;95:145-50.

23. Estévez M, Cava R. Effectiveness of rosemary essential oil as an inhibitor of lipid and protein oxidation: contradictory effects in different types of frankfurters. Meat Sci 2006;72:348-55.

24. Santé-Lhoutellier V, Engel E, Aubry L, et al. Effect of animal (lamb) diet and meat storage on myofibrillar protein oxidation and in vitro digestibility. Meat Sci 2008;79:777-83.

25. Hofmann K, Hamm R. Sulfhydryl and disulfide groups in meats. Adv Food Res 1978;24:1-111.

26. Jongberg S, Skov SH, Tørngren MA, et al. Effect of white grape extract and modified atmosphere packaging on lipid and protein oxidation in chill stored beef patties. Food Chem 2011;128:276-83.

27. Lutolf MP, Tirelli N, Cerritelli S, Cavalli L, Hubbell JA. Systematic modulation of Michael-type reactivity of thiols through the use of charged amino acids. Bioconjug Chem 2001;12: 1051-6.

28. Takeo N, Kyozo S. The aldol condensation reaction of n-saturated aldehyde in the presence of phosphatidyl ethanolamine. Nippon Nōgeikagaku Kaishi 1973;417:313-9. (in Japanese)

29. Okoń A, Stadnik J, Dolatowski ZJ. Effect of probiotic bacteria on antiradical activity of peptides isolated from dry-cured loins. Cyta J Food 2017;15:382-90. 
30. Hes M, Pyrcz J. Influence of lipid stabilization on the retention of available lysine and methionine in stored raw Polish sausage. Particle Accelerator Conference 2005;2009:3724-6.

31. Morrissey PA, Sheehy PJA, Galvin K, et al. Lipid stability in meat and meat products. Meat Sci 1998;49S1:S73-86.

32. Estévez M, Ollilainen V, Heinonen M. Analysis of protein oxidation markers alpha-aminoadipic and gamma-glutamic semialdehydes in food proteins using liquid chromatography (LC)-electrospray ionization (ESI)-multistage tandem mass spectrometry (MS). J Agric Food Chem 2009;57:3901-10.

33. Faustman C, Sun Q, Mancini R, et al. Myoglobin and lipid oxidation interactions: mechanistic bases and control. Meat Sci 2010;86:86-94.

34. Van CD. Enhancement of iron absorption from ligated segments of rat intestine by histidine, cysteine, and lysine: effects of removing ionizing groups and of stereoisomerism. J Nutr 1973;103:139-42.

35. Zhou CL, Ye HQ, Wang H, et al. Coordination of L-arginine and iron cation improves stability of hemoglobin concentrates. Eur Food Res Technol 2015;240:743-51.

36. Bai Y, Qin BY, Liu Y, Hong W, Zhou YF. Study on superoxide anion radical scavenging activity of seleno-sulfur-containing amino acid. Acta Nutr Sin 2009;31:26-9.

37. Dabbou S, Gai F, Renna M, et al. Inclusion of bilberry pomace in rabbit diets: Effects on carcass characteristics and meat quality.
Meat Sci 2017;124:77-83.

38. Frankel EN. Lipid oxidation: mechanisms, products and biological significance. J Am Oil Chem Soc 1984;61:1908-17.

39. Xiong Q, Li X, Zhou R, et al. Extraction, characterization and antioxidant activities of polysaccharides from $E$. corneum gigeriae galli. Carbohydr Polym 2014;108:247-56.

40. Li XJ, Cui SY. DPPH radical scavenging mechanism of ascorbic acid. Food Sci 2011;32:86-90. (in Chinese)

41. Fiorucci S, Golebiowski J, Daniel Cabrolbass A, et al. DFT study of quercetin activated forms involved in antiradical, antioxidant, and prooxidant biological processes. J Agric Food Chem 2007;55:903-11.

42. Van CD. Enhancement of iron absorption from ligated segments of rat intestine by histidine, cysteine, and lysine: effects of removing ionizing groups and of stereoisomerism. J Nutr 1973;103:139-42.

43. Sun B, Belchior GP, Ricardo-Da-Silva JM, et al. Isolation and purification of dimeric and trimeric procyanidins from grape seeds. J Chromatogr A 1999;841:115-21.

44. Gao HB. Organic chemistry. In: Gao HB, editor. Amino acid, protein and nucleic acid. Beijing, China: Higher Education Press; 2005. pp. 612-33. (in Chinese)

45. Xuan-Jun LI, Cui SY. DPPH radical scavenging mechanism of ascorbic acid. Food Sci 2011;32:86-90. 